\title{
Voltage Sag Compensation of Transmission Line System by using Thyristor Controlled Series Capacitor
}

\author{
B.Narsimha Reddy ${ }^{1}$, Gumalapuram Gopal ${ }^{2}$ \\ Assistant Professor, Department of EEE, Mahatma Gandhi Institute of Technology, Hyderabad, Telangana, India ${ }^{1}$ \\ Assistant Professor, Department of EEE, Mahatma Gandhi Institute of Technology, Hyderabad, Telangana, India ${ }^{2}$
}

\begin{abstract}
The rapid increase in industrial load created the lack of power generation capacity and transmission line instability problems. The consequence of this is decrease in Power Quality (PQ) and produces the voltage sag, voltage swell, flickers, and harmonics. The usage of power electronic devices for power conversion also causes the problem and generates excessive voltage fluctuations in the system. FACTS devices made it possible to reduce the PQ issues. This paper developed the control strategy for series compensation to eliminate voltage sag and harmonic distortion in transmission system with the application of Custom Power Device (CPD) of type Thyristor Controlled Series Capacitor (TCSC). This is power electronics device used to enhance the power transfer capability near thermal limit without affecting the stability. The results obtained through MATLAB/SIMULINK environment when TCSC is inserted in series with the transmission line are shown. By the proposed method, the Total Harmonic Distortion (THD) also kept at lower than $5 \%$ as per IEEE-519 standard.
\end{abstract}

KEYWORDS: Power Quality, Voltage Sag, Voltage Swell, Harmonics, TCSC, Total Harmonic Distortion

\section{INTRODUCTION}

Power Quality in electric power system is one of the important areas to be study and research. According to the IEEE definition, FACTS is defined as "The flexible AC Transmission System (FACTS) is a new technology based on power electronic devices which offers an opportunity to enhance controllability, stability and power transfer capability of AC Transmission Systems". The FACTS technology can control voltage magnitude, phase angle and circuit reactance so it is redistributed in the load flow and regulate bus voltage. So, these devices give a greater flexibility regarding the type of control actions that can be taken at any given time [1]. FACTS devices are achieved through switched or controlled shunt compensation, series compensation or phase shift control. The devices work electrically as fast and the reaction time allowed by power electronic is very short. The classification of FACTS devices based on the connection is shown in Fig.1. [2].

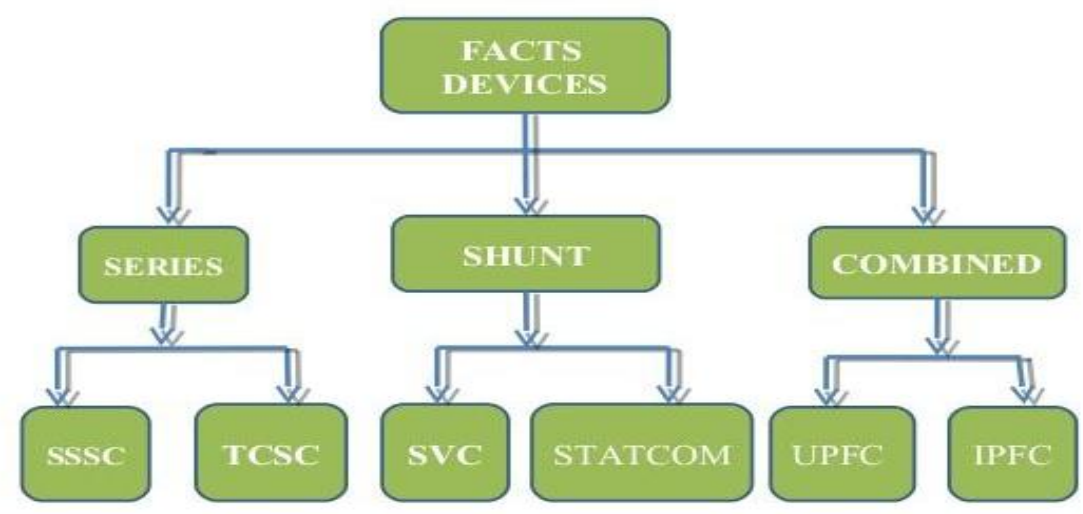

Fig.1. Classification of FACTS devices based on the connection 
The FACTS devices form a large group of power electronic based converters designated to enhance controllability and increase power transfer capacity. These devices can be classified into two groups:

\section{Thyristor based FACTS devices}

2. Converter based FACTS devices

The FACTS devices use conventional thyristors in building the circuit. If the FACTS devices use thyristors without self-turn-off ability, the device is called a thyristor controlled device. If the thyristor in the FACTS device can be turned off by applying appropriate gate voltage, the device is called a thyristor switched device. The TCSC is one of the powerful thyristor based FACTS devices.

\section{Thyristor Controlled Series Capacitor (TCSC)}

Thyristor Controlled Series Compensator (TCSC) device is a series compensator to control the power flow by compensating the reactance of the transmission line which improves the transient stability. Most of the researchers explained that TCSC deals with steady state and dynamic control and applications independently. This paper explains the proper selection of capacitor and inductor values of the TCSC device which can be realized through reactance equation leads to capacitive and inductive reactance compensations. While designing, TCSC parameters can also be selected as per requirement on end side demands and for safe operating span of a TCSC. It consists of the series compensating capacitor shunted by a Thyristor-Controlled Reactor [2] as shown in Fig.2.

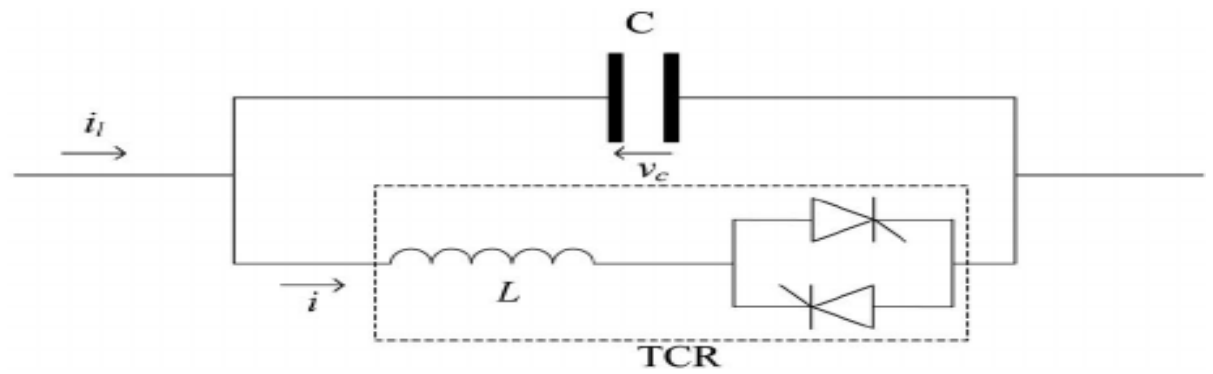

Fig.2. Thyristor Controlled Series Compensator Configuration

However, to fully understand and properly utilize these types of controllers, a number of control tasks for both dynamic and steady state system improvement must be jointly considered. Since the time frames of the different control actions comprise a wide range of system responses, a hierarchical control scheme should be preferably considered for the controller. In the case of a TCSC, such a scheme should consider the different control levels acting on the same control variable, which in this paper is assumed to be the fundamental frequency equivalent impedance, as this is the control variable most commonly studied. Voltage sags are related to power quality problems is usually leads to the fault in the power system and switching actions including open and close interval to isolate the faulted sections. They are characterized by RMS voltage variations outside the normal operating range of voltages. Voltage sag is a short-duration reduction in RMS voltage caused by faults on the power system and the starting of large loads, such as motors. Voltage sag causes a complete loss of voltage and a common result of the actions taken by utilities to clear transient faults on their systems [3]. In this paper our objective is to analyze the voltage profile of receiving end for transmission line using MATLAB simulation. Simulation is done for $400 \mathrm{kv}$ transmission line for the analysis of voltage sag with and without TCSC.

The basic idea behind the TCSC scheme is to provide a continuously variable capacitor by means of partially cancelling the effective compensating capacitance by the TCR. The TCR at the fundamental system frequency is continuously variable reactive impedance; controllable by delay angle $\alpha$, the steady-state impedance of the TCSC is that of a parallel $L C$ circuit, consisting of a fixed capacitive impedance, $X_{C}$, and variable inductive impedance, $X_{L}(\alpha)$.

The TCSC thus presents a tuneable parallel LC circuit to the line current that is substantially a constant alternating current source. As the impedance of the controlled reactor, $\mathrm{X}_{\mathrm{L}}(\alpha)$, is varied from its maximum (infinity) toward its minimum $(\omega \mathrm{L})$, the TCSC increases its minimum capacitive impedance, $X_{\mathrm{TCSC}} \cdot \min =\mathrm{X}_{\mathrm{C}}=1 / \omega \mathrm{C}$, (and thereby the degree of series capacitive compensation) until parallel resonance at $X_{C}=X_{L}(\alpha)$ is established and $\mathrm{X}_{\mathrm{TCSC}} \cdot \max$ theoretically becomes infinite. Decreasing $\mathrm{X}_{\mathrm{L}}(\alpha)$ further, the impedance of the TCSC, $\mathrm{X}_{\mathrm{TCSC}}(\alpha)$ becomes inductive, reaching its minimum value of $\mathrm{X}_{\mathrm{L}} \mathrm{X}_{\mathrm{C}} /\left(\mathrm{X}_{\mathrm{L}}-\mathrm{X}_{\mathrm{C}}\right)$ at $\alpha=0$, where the capacitor is in effect bypassed by the TCR. Therefore, with the usual TCSC arrangement in which the impedance of the TCR reactor, $\mathrm{X}_{\mathrm{L}}$, is smaller than 


\title{
| e-ISSN: 2319-8753, p-ISSN: 2320-6710| www.ijirset.com | Impact Factor: 7.512|
}

\author{
||Volume 9, Issue 6, June 2020\|
}

that of the capacitor, $X_{C}$, the TCSC has two operating ranges around its internal circuit resonance: one is the $\alpha_{\text {Clim }} \leq \alpha$ $\leq \pi / 2$ range, where $X_{\mathrm{TCSC}}(\alpha)$ is capacitive, and the other is the $0 \leq \alpha \leq \alpha_{\mathrm{Clim}} \leq \pi / 2$ range, where $\mathrm{X}_{\mathrm{TCSC}}(\alpha)$ is inductive. An appropriate value for capacitor and inductor of a TCSC device is based on the net reactance of transmission line and expected power demands in future. Capacitor value is chosen by a degree of series compensation. Sub section gives an idea of selecting degree of series compensation. Choice of inductor depends on the length of operating area required for inductive and capacitive region. It is perfectly decided by a factor „, $\omega^{\text {ee }}$, given by shifting the position of resonance region. The FACTS devices have low switching frequency of once a cycle in the converters and hence the have low losses. The thyristor can be also used to simply bridge impedances in the valves.

\section{Simulation DiagRAM \& RESULTS}

In the proposed system, a $3-\mathrm{Ph} 400 \mathrm{kv}, 364 \mathrm{~km}$ long transmission is developed in a MATLAB/SIMULINK environment. The 3-Ph transmission line without TCSC connection is shown in Fig.3. and also the corresponding voltage sag is produced during 0.4 to $0.8 \mathrm{sec}$ by switching the heavy load \& total harmonic distortion analyzed and shown in Fig.4 \& Fig.5. at receiving end. The THD value obtained without TCSC is $9.07 \%$.

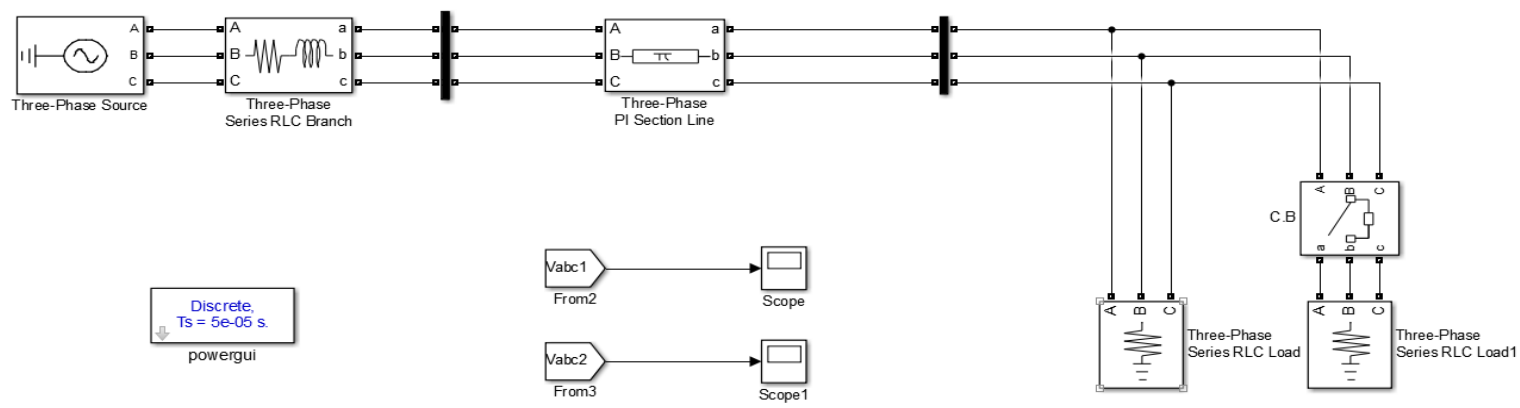

Fig.3.Simulation diagram of 3-Phase 3-wire system without TCSC

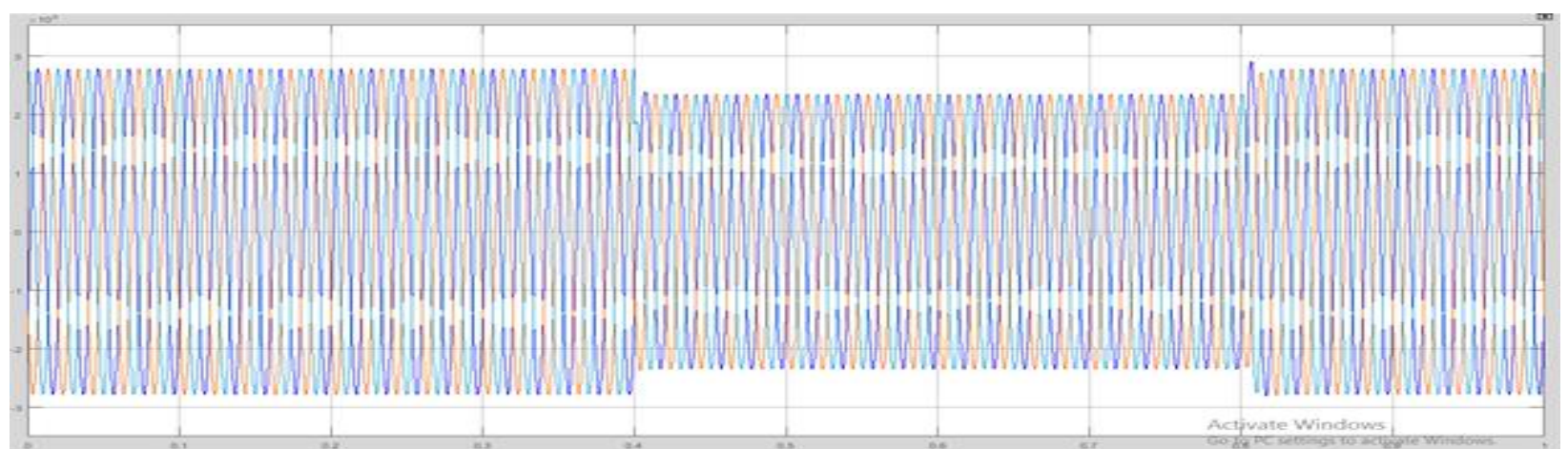

Fig.4.Voltage Sag during 0.4 to $0.8 \mathrm{Sec}$ by switching heavy load of 3-Phase 3-wire system without TCSC 
\|Volume 9, Issue 6, June 2020\|

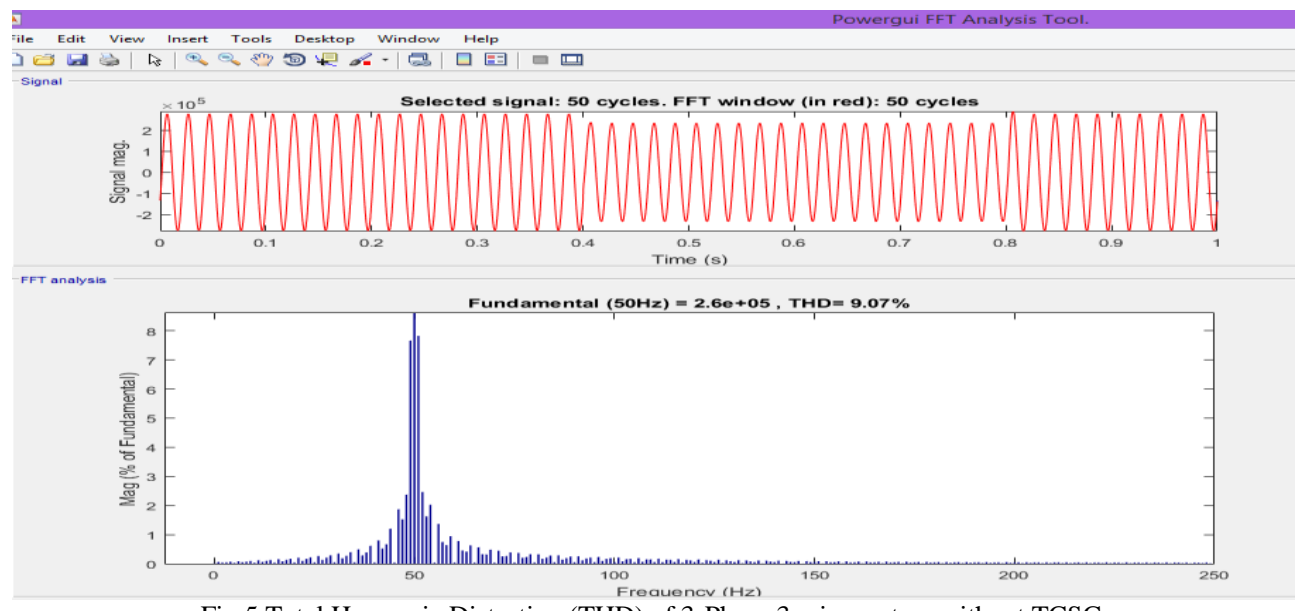

Fig.5.Total Harmonic Distortion (THD) of 3-Phase 3-wire system without TCSC

The 3-Ph transmission line with TCSC connection is shown in Fig.6. The corresponding voltage sag is produced during 0.4 to $0.8 \mathrm{sec}$ by switching the heavy load \& total harmonic distortion analyzed and shown in Fig. 7 \& Fig.8. at receiving end. The THD value obtained without TCSC is $4.82 \%$ and improved the voltage profile also.

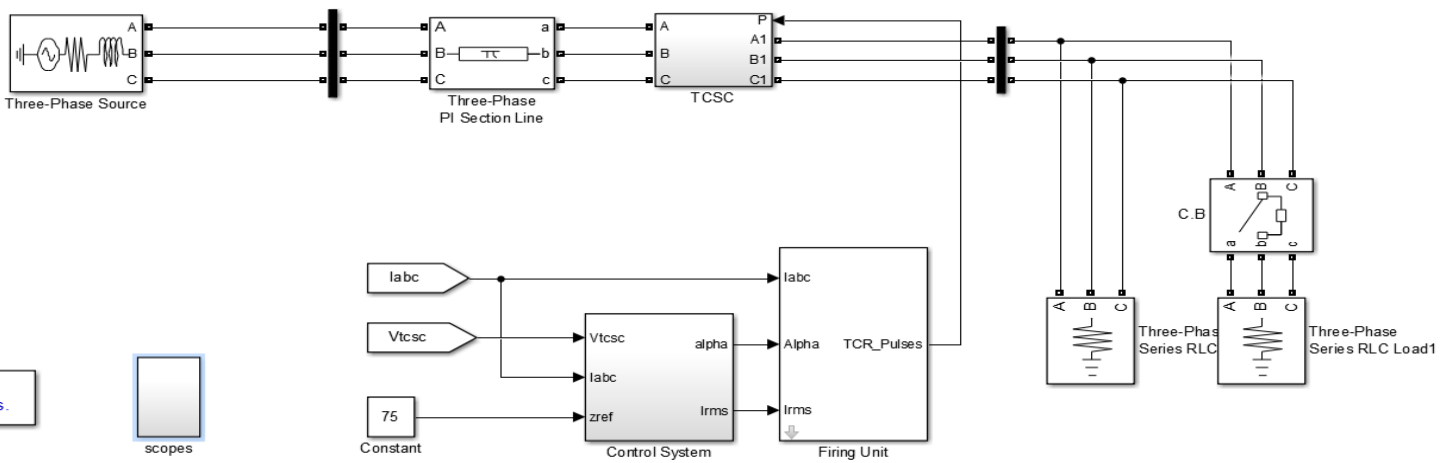

Fig.6.Simulation diagram of 3-Phase 3-wire system with TCSC

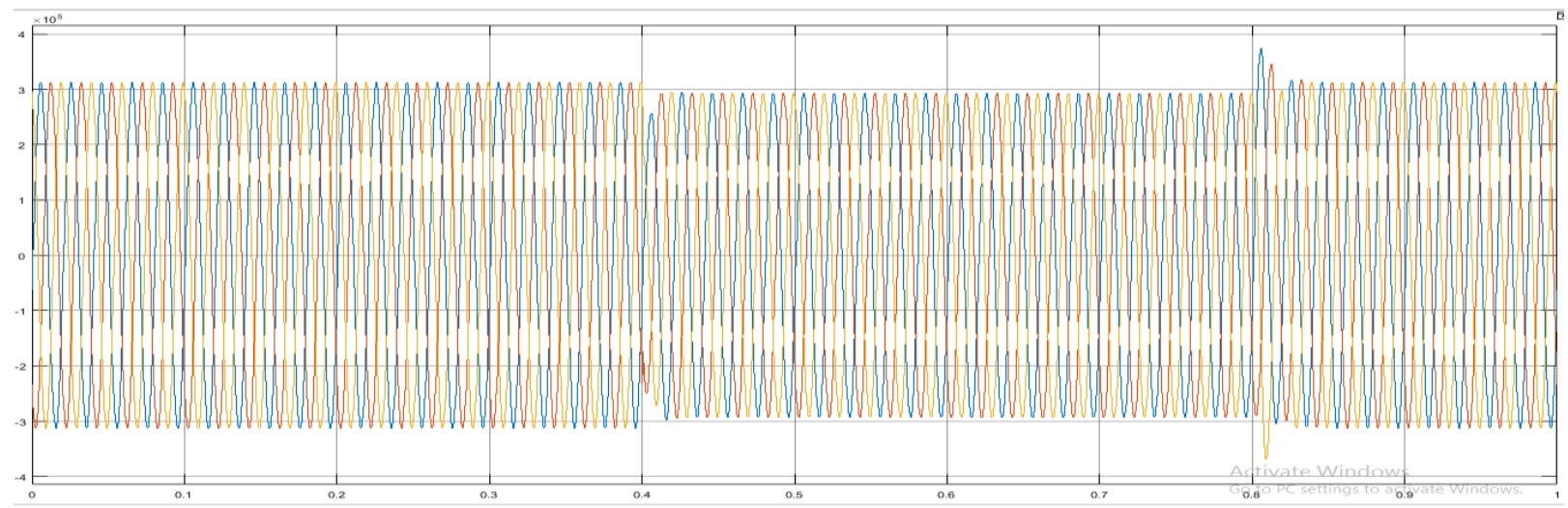

Fig.7.Voltage Sag during 0.2 to 0.4Sec by switching heavy load of 3-Phase 3-wire system with TCSC 


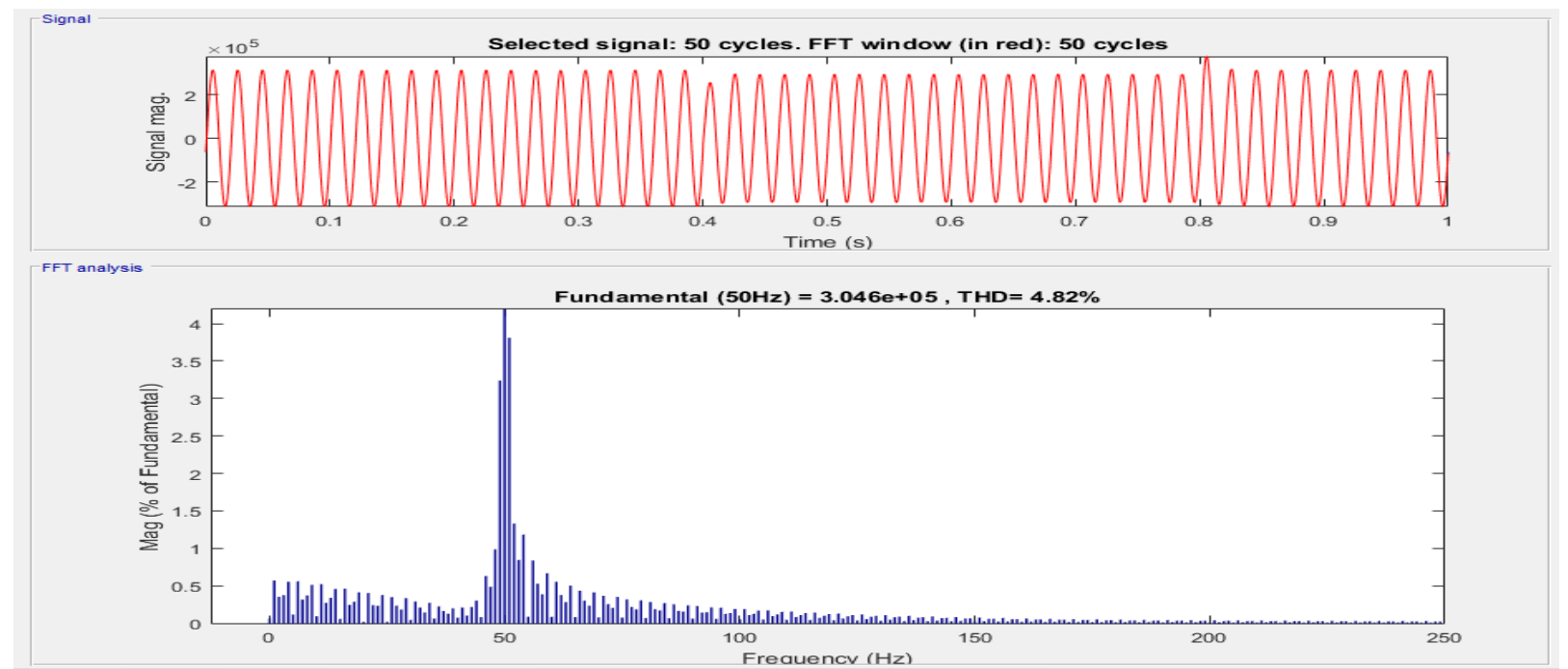

Fig.8.Total Harmonic Distortion (THD) of 3-Phase 3-wire system with TCSC

Table.1.Summary of THD without and with TCSC in transmission line

\begin{tabular}{|c|c|c|}
\hline $\begin{array}{c}\text { Sending End } \\
\text { Voltage in KV } \\
(\mathrm{Ph} \text { to } \mathrm{Ph})\end{array}$ & $\begin{array}{c}\text { Total Harmonic } \\
\text { Distortion in } \% \\
\text { without TCSC }\end{array}$ & $\begin{array}{c}\text { Total Harmonic } \\
\text { Distortion in \% with } \\
\text { TCSC }\end{array}$ \\
\hline 400 & 9.07 & 4.82 \\
\hline
\end{tabular}

\section{CONCLUSION}

TCSC is successfully implemented a proposed system for non-linear load in order to compensate the voltage sag. For power flow improvement, the constant power control circuit is developed to tune the TCSC as required. In this paper, we can see that the voltage sag is generated during sudden switching on/off of heavy loads, when TCSC is not inserted. This voltage sag has been compensated with the use of TCSC as described above. Finally, we conclude that with the use of TCSC the sag can be compensated, and hence the power transfer capability of line can be improved and the load voltage is maintained within the limit. Harmonic analysis is also done for both the conditions of voltage sag and voltage swell and THD is reduced to $4.82 \%$

\section{REFERENCES}

[1] Rathore, Uma \& Dharmendra, Kumar \& Singh, Dharmendra. (2016). A Study to Improve the Power Quality of Transmission Line Using TCSC. 10.4010/2016.569. 10.4010/2016.569.

[2] S.Sreejith, Sishaj P Simon, M P Selvan. "Power Flow Analysis Incorporating Firing Angle Model Based TCSC".

[3] GABRIEL OLGUIN "Voltage Dip (Sag) Estimation in Power Systems based on Stochastic Assessment and Optimal Monitoring” 2005 ISBN 91 7291-594-3 Doctor Savhandlingar vid Chalmers Tekniska Högskola Ny serie nr 2276 ISSN 0346-718.

[4] N. G. Hingorani and L. Gyugyi, Understanding FACTS: Concepts and Technology of Flexible AC Transmission Systems. New York: IEEE Press, 2000. 